\title{
USOS DE SEX TOYS: \\ A CIRCULAÇÃO ERÓTICA ENTRE OBJETOS E PESSOAS
}

\author{
Maria Filomena Gregori
}

Examinar o mercado erótico contemporâneo permite vislumbrar dinâmicas que revestem as relações entre corpos e pessoas e desafia pensar sobre os limites materiais do corpo como algo em separado daquilo que designa pessoas. Este artigo discute tais questões envolvidas sobretudo nas experiências de consumo de sex toys por usuários, tentando dar ênfase à própria noção de uso: as práticas concretas e localizadas que mobilizam todo um repertório de convenções de gênero e sexualidade. Usos que importam analiticamente por indicarem que as experiências sexuais se dão de modo mais polimorfo entre adultos do que se admite socialmente. Freud, em seu Três ensaios da sexualidade (1972 [1905]), lançou a ideia de que a sexualidade é polimorfa e perversa na infância. Diferente do que se alega em determinados círculos críticos à psicanálise, esta noção veio a romper com o significado de perversão adotado em alguns âmbitos médico-legais do século XIX, que a concebiam como desvio às normas ou propriamente como patologia. Freud tomava a perversão, expressa na polimorfia da sexualidade infantil, como constitutiva da normalidade. ${ }^{1} \mathrm{Na}$ maturidade, a tendência seria de represamento desse polimorfismo perverso, em direção à organização das pulsões, a serviço da função reprodutora e com a finalidade de atingir um objeto sexual.

Assim sendo, mesmo que admitamos que Freud criou as bases de contestação à sexologia de seu tempo ao ressaltar a plasticidade da sexualidade humana e que não há uma sexualidade natural (as escolhas sexuais são produções de desejo formadas na infância e também resultantes da vida adulta), ele supunha um processo de crescente organização das pulsões, no qual as zonas erógenas passariam a subordinar-se ao genital, bem como a libido (autoerótica) a se dirigir para um objeto cada vez mais definido. Os relatos e as histórias que apresento a seguir são enunciados por pessoas adultas que experimentam seus corpos, criando zonas de prazer além das fronteiras genitais, não permitindo afirmar que os objetos, investidos libidinalmente, sejam inteiramente definidos ou estáveis. 
Não se trata aqui de contestar os pressupostos da teoria da sexualidade, mas problematizar, a partir de trajetórias sexuais e afetivas de homens e mulheres, nos seus relacionamentos hetero ou homossexuais, a suposta ideia de que os processos para alcançar a maturidade direcionam e organizam desejos e prazeres, afastando polimorfismos. Questionar o alcance desta noção é relevante, principalmente por ela não se limitar ao campo da sexologia ou da psicanálise, mas por estar difusa e ser ainda bastante significativa na manutenção das normas vigentes de gênero e sexualidade.

Ao conversar com as pessoas sobre suas experiências sexuais, notei a ausência de explicações ou regularidades. ${ }^{2}$ Reuni um material que não apresenta recorrências que possam ser tomadas como representativas de comportamentos "normais", "saudáveis" ou "desviantes", tampouco de carreiras sexuais masculinas ou femininas, heterossexuais ou homossexuais. Antes, analiso um conjunto rico de narrativas que indicam mudanças ou inflexões nas dinâmicas que operam os dispositivos da sexualidade. ${ }^{3}$ As pessoas entrevistadas e todas, em maior ou menor intensidade, sozinhas ou acompanhadas por outras pessoas e pelos objetos praticam sexo, deslocando os termos que compõem essa matriz. Mesmo dentre aqueles que classificaríamos como heterossexuais, é possível perceber afastamento das normas e, em particular, dissociações entre prática e identidade, em um exercício quase permanente de polimorfismo sexual.

Começo com um caso paradigmático de uma mulher de 41 anos, psicóloga e ativista de variadas causas relacionadas à sexualidade. ${ }^{4}$ Ela está no quarto casamento: o primeiro foi com uma mulher e durou dez anos, o segundo foi com um homem homossexual soro-positivo e durou quatro anos, o terceiro com um heterossexual que ela chama de coisa (por ser uma pessoa com quem não tem afinidades) e com quem ficou casada dois anos, e está, há um ano, com um rapaz português e heterossexual. Desde criança, teve namoradinhas e namoradinhos, mas foi apenas a partir dos 17 anos que teve contato sexual com homossexuais, ao ingressar no curso de teatro. Dessa experiência e do convívio com pessoas GLBT (o termo é empregado por ela) resultou a participação no grupo de mulheres.

Eu fui muito apaixonada pela minha primeira mulher, loucamente apaixonada e aí foi que a gente começou a transar. E era muito diferente, transar com menino é muito diferente de transar com menina. Eu lembro que as pessoas perguntavam: "o que é mais gostoso, transar com menino ou com menina?". Os dois. "Mas o que é melhor?" Não sei, acho que os dois. "Você não sente falta?" Falta do quê? Quando você está com um, está com um, quando está com outro, está com outro, não existe essa coisa de déficit, não rola isso, porque é muito diferente! 
Seu relato impressiona tanto pela diversidade de elementos como pelo ritmo da narrativa e os termos empregados. Ela conta que, na infância, já beijava a irmã e uma amiguinha e que, no final da adolescência, se apaixonou por um namorado com quem, ainda virgem e com medo de engravidar, praticou sexo anal. Aliás, a prática durou quase um ano, sem que mencione qualquer episódio de dor ou desconforto, ainda antes de perder o hímen. Ao perdê-lo, afirma ter tido uma ejaculação feminina. É praticante de fist fucking e aprendeu a fazer sexo plastificada, no relacionamento com o marido soro-positivo. Além de todas essas experiências, ela relata o tempo longo em que fez sexo pela internet com o atual marido português e com um dildo, que a acompanhou por 12 anos.

Sua entrevista traz a eloquência narrativa das histórias de Juliette, famosa libertina de vários livros do Marquês de Sade. ${ }^{5}$ Cada episódio em que ela está presente constitui uma aventura com um personagem marcante da corte: um juiz, uma condessa, um barão ou um bispo. Certamente, no caso de Sade, a diversidade está relacionada às convenções do erotismo literário do século XVIII e à importância da paródia política que nelas há. Angela Carter (1978) afirma que Juliette é uma personagem que jamais perdeu atualidade: é possível tecer analogias entre ela e as mulheres que lutaram pela liberação sexual dos anos 60, guerrilheiras transgressoras e também eloquentes. Não estranha, nesse sentido, a possibilidade de um paralelo.

A entrevistada é, até pela experiência militante, uma libertária. Mas seu ativismo não se expressa apenas na forma prática da política. Além de sua história ser uma espécie de contraexemplo a qualquer linearidade na correspondência entre eventos com algo que poderia ser chamado de formação ou amadurecimento sexual, sua trajetória é uma aventura narrada. Parece ter cumprido uma espécie de compêndio: do pretenso polimorfismo perverso infantil, ela migra para o sexo anal, o sexo com mulheres, com homens, homossexuais e heterossexuais, sexo presencial e virtual, com gente e com objetos. Sua disposição para o sexo é permanente. Mas essa qualidade ou natureza incansável é também um ritmo discursivo que a aproxima de Juliette. Na literatura libertina e na política libertária é possível testemunhar uma intensidade e uma diversidade de composições que contrastam com o teor monossilábico, tímido e, por vezes, apenas evocativo que notei em outras entrevistas.

Falar sobre o sexo constrange, ainda mais se o convite sugere discorrer sobre predileções e fantasias que envolvem ou articulam a imaginação às convenções normativas, ao corpo e suas sensações e fluidos. As entrevistas são todas recortadas por risos. As conversas têm algumas esquisitices que são, inegavelmente, engraçadas. Mas há uma variedade de risos: rictus 
nervosos, em alguns casos, e risos de relaxamento, em outros. Nessas diferentes expressões, vale notar que o riso parece preencher algo inefável à narrativa. É precisamente essa qualidade "indizível" ao tratar os aspectos concretos do sexo que é contrastante com a discursividade quase guerrilheira da entrevistada. Sua loquacidade, contudo, mais do que uma liberdade sem normas ou uma marca de estilo individual, interessa, na medida em que tanto a semântica quanto a sintaxe do discurso revelam convenções. ${ }^{6}$

As aventuras de Juliette expressam, em alguma medida, aspectos idiossincráticos da passagem do iluminismo aristocrático para o republicano. As convenções reveladas pela narrativa da entrevistada têm a ver, ao que parece, com aquilo que já pode ser tomado como temas e prescrições politizadas. Mas não só. Ela, além de ativista, é uma consumidora do mercado erótico, uma usuária da internet, alguém que gosta de bens eróticos. Sua fala expressa convenções que estão sendo criadas ou mantidas no marco da vida urbana e contemporânea, exposta ao repertório sociocultural que a constitui. Exprime o peso acentuado que a fruição sexual passou a ter: sua legitimidade e visibilidade, os termos e os temas que são mobilizados em torno dela.

A sensação com que se fica é a de que, no mundo atual, o que não é mais possível é a ausência de interesse pelo sexo. Interesse que suprime as fronteiras de sexo, de gênero, de idade (com exceção das crianças), de nacionalidade, de classe, e também do que se pode aferir como alguns limites corporais - o que, em tese, produz dor pode legitimamente ser sentido como prazeroso. Sabemos que o sexo foi uma invenção criada pelos dispositivos da sexualidade e, nos termos de Foucault (1976), suas expressões normativas foram sendo gestadas em meio às instituições e às práticas de saber-poder desde o século XVIII. Assistimos atualmente a um conjunto de prescrições que, antes de serem modos de controle ou produções de perversões, demandam a atividade, a criatividade e a diversificação. Inclusive, todo o esforço de Foucault em tentar persuadir sobre a natureza produtiva dos dispositivos que, em vez de calarem e reprimirem, incitavam, parece estar inteiramente em operação. Além disso, é preciso reconhecer que tais prescrições são difundidas em variados âmbitos, havendo, entretanto, um protagonismo significativo do mercado. O conjunto de suas ações passou a fornecer, para um contingente maior de agentes, o acesso aos elementos que permitem a diversificação de práticas sexuais. Não estou apenas me referindo aos bens e aos objetos produzidos e comercializados, mas aos serviços sexuais, aos ambientes de encontro, presenciais e virtuais. Nesse sentido, a narrativa exuberante da entrevistada revela um estilo singular - que tem a ver com sua trajetória pessoal - mas inteiramente tecido em meio aos fios que tramam os repertórios de que dispomos. 
Outra dimensão que sobressai, em seu testemunho, tem a ver com um aspecto da vida contemporânea que tem cada vez chamado mais a atenção: sua narrativa indica um foco de atuações, reflexões e demandas que constitui uma espécie de corporalidade erótica, e não propriamente questões de identidade ou de direitos, a decidir por esta ou aquela orientação sexual. Não é um corpo minimamente estabilizado pelas convenções que definem feminilidade, masculinidade ou aquelas que instituem as zonas de prazer ou sobre as quais incidem tabus. Trata-se de processos práticos de articulação entre corpos e erotismos. O que foi outrora definido como perversão passa a estimular e a fornecer mapas libidinais e a indicar alternativas variadas e não previstas. Assim, o que é constrangimento num determinado momento passa a constituir o índice que proporciona prazer em outro, e assim sucessivamente. E para pensar mais adensadamente sobre essas corporalidades eróticas, vale examinar como esses corpos são tocados não apenas por outros corpos, mas também por objetos.

\section{Bens eróticos ou agentes eróticos?}

Em 2002, a filósofa espanhola Beatriz Preciado publicou, na França, o seu manifesto contrassexual e afirmou se tratar de um texto sobre os sexos de plástico e sobre a plasticidade dos sexos: uma reflexão provocativa, na qual o dildo ${ }^{7}$ ocupa o lugar estratégico de tecnologia de resistência ou, como nos seus próprios termos, de formas de contradisciplina sexual. Ela sugere que é hora de aprendermos com o dildo, este "objeto móvel, que é possível deslocar, desatar e separar do corpo, caracterizado pela reversibilidade no uso, e que ameaça constantemente a estabilidade das oposições dentro/ fora, passivo/ativo, órgão natural/máquina, penetrar/cagar, oferecer/tomar" (Preciado 2002:70).

Em anexo instrutivo do livro, Preciado informa que objetos feitos em madeira ou couro, imitando o membro viril e untados com azeite de oliva, aparecem em indícios escritos relativos a jogos sexuais que datam do séc. III d.C., na cidade de Mileto, conhecida pela fabricação e exportação de Olisbos (nome desses objetos empregados pelas mulheres na masturbação). O termo dildo aparece em inglês a partir do século XVI e deriva do italiano diletto, que quer dizer prazer ou gozo. Aliás, to dildo no inglês clássico significa acariciar sexualmente uma mulher. Ela menciona também outros sentidos da palavra: estúpido ou idiota e a associação etimológica, no castelhano, com dilección, o que significa vontade honesta e amor. Assim, mais do que um objeto funcional, a autora quer chamar a atenção para aquilo que o 
dildo passa a evocar ou a sugerir: algo que se refere ao prazer feminino, que se aproxima - sem ser - do membro viril masculino, trazendo ainda referências à estupidez e ao laço amoroso.

Independente da investigação da origem da palavra ou de seus usos mais remotos, o tratamento deste objeto pela autora instiga a imaginação. Por meio do dildo e de seu uso é possível antever a desestabilização das distinções entre o imitado e o autêntico, entre a referência e o referente, entre natureza e artifício e entre os órgãos sexuais e as práticas sexuais. Trata-se de pensar a relação entre corpos e objetos sexuais, lançando mão de uma noção indicada por Gayle Rubin (2003), de que os variados fetichismos são inteligíveis no momento em que situamos suas histórias, rotas espaciais e materiais. Antes de se constituírem como perversões marginais em relação às normatividades sexuais e de gênero, tais práticas estão imersas nos processos da produção moderna do corpo e de sua conexão com os objetos manufaturados.

\begin{abstract}
Não vejo como se possa falar de fetichismo, ou sadomasoquismo, sem pensar sobre a produção da borracha, nas técnicas e acessórios usados para o manejo de cavalos, no brilho dos calçados militares, na história das meias de seda, no caráter frio e oficial dos instrumentos médicos ou no fascínio das motocicletas e a liberdade enganosa de sair da cidade para pegar a estrada. A propósito, como podemos pensar sobre o fetichismo sem considerar o impacto das cidades, de certas ruas e parques, de zonas de prostituição e de "diversão barata", ou da sedução das lojas de departamentos, com suas pilhas de mercadorias desejáveis e glamurosas? (Rubin; Butler 2003:179).
\end{abstract}

Tal articulação entre a produção de objetos em meio a processo social e as normas sexuais e de gênero está na base, por exemplo, da criação do vibrador, de sua incorporação pelo mercado consumidor, bem como dos usos que transgridem as funções originalmente planejadas. Sua origem está associada à histeria.

Elaine Showalter (1987) chama a atenção, ao estudar as articulações paradoxais entre mulheres e modalidades de doença dos nervos em cenário britânico, para o fato de que, embora a histeria tenha sido considerada, por séculos, uma doença feminina (a palavra histeria é derivada do grego hysteron, útero), ela assumiu centralidade no discurso médico e nas definições de feminilidade e, mais propriamente, de sexualidade feminina entre 1870 e a Primeira Grande Guerra Mundial. Nesse período, a psiquiatria, em geral, e as vertentes influenciadas pelo evolucionismo darwinista, em particular, ${ }^{8}$ associavam explicitamente a neurastenia, a anorexia nervosa e 
a histeria aos perigos resultantes das ambições geradas pela ampliação de oportunidades abertas às mulheres, sobretudo na educação e no mercado de trabalho. ${ }^{9}$ Muitas batalhas foram travadas entre autoridades médicas e feministas (entre elas, algumas médicas como Mary P. Jacobi e Elizabeth G. Anderson) em função precisamente da estreita vinculação entre a histeria e a figura da "Nova Mulher" novecentista: ilustrada e sufragista.

Em meados do século XIX, Robert B. Carter publica um estudo clássico, associando a histeria à frustração ou a desordens de natureza sexual e, a partir daí, são criadas técnicas variadas para o tratamento. De um lado, procedimentos de rememoração pela hipnose, como a técnica desenvolvida por Jean-Martin Charcot (1825-1893) que, segundo Freud, legitimou a histeria como uma doença. ${ }^{10}$ De outro lado, foi elaborado, segundo Showalter, todo um sistema de curas que incluía tônicos, banhos (duchas e banhos de imersão) e, em alguns casos, empregavam-se choques elétricos de modo a estimular nervos e músculos. Foi nesse período, mais precisamente em 1869, que o médico norte-americano George Taylor inventou um massageador vibratório, movido a vapor, com a finalidade de tratar "distúrbios" femininos relacionados a este mal - ansiedade, insônia, irritabilidade. Na década seguinte, um médico inglês, Joseph Mortimer Granville, criou um aparelho de modelo mais portátil e movido à bateria. ${ }^{11}$ Data de 1899 a publicação da primeira propaganda nos Estados Unidos desses instrumentos elétricos para usos médicos em catálogos como Home Needlwork Journal e, no ano seguinte, nos catálogos da Sears. ${ }^{12}$

Raquel Maines (1999) assinala que a intervenção tecnológica na sexualidade foi não só uma constante na modernidade, mas também que essa criação aponta para aspectos importantes das noções forjadas sobre o prazer sexual. O tratamento da histeria com o uso das vibrações (no início, controlado exclusivamente pelos médicos) foi acompanhado pela criação de instrumentos para evitar a masturbação com as mãos. ${ }^{13}$ Ainda que inúmeros males já tivessem sido atribuídos à masturbação, foi apenas a partir do século XVIII que ela se tornou doença. ${ }^{14} \mathrm{Um}$ século mais tarde, registrados como cintos de castidade, muitos desses aparatos foram mecanizados e eletrificados com a comercialização das baterias.

Paradoxal e interessante é essa convivência entre a repressão à masturbação e as técnicas de cura da histeria por intermédio de objetos que servirão de modelo prostético para os acessórios eróticos contemporâneos. Como salienta Preciado, o vibrador e o tratamento da histeria, no século XIX, destacaram um modelo de corpo no qual a paciente que se mostrava indiferente ao coito heterossexual era descrita como carente de energia sexual, energia esta suplementada pela máquina. Foi elaborada também a noção de que o orgasmo 
opera no espaço de interseção de duas lógicas opostas: doença (masturbação) e cura (histeria), veneno e remédio. Aliás, a tensão entre o uso de vibradores, como remédio e como veneno, permaneceu viva, tal o receio dos médicos de que, com o uso descontrolado desses apetrechos, a cura da histeria pudesse resultar em vaginismo ou lesbianismo (Maines 1999).

O controle médico dos vibradores foi predominante até os anos 20 do século passado, quando o mercado norte-americano passou a divulgar produtos semelhantes, como presentes que os maridos poderiam comprar para suas esposas. ${ }^{15}$ Tal divulgação, no entanto, teve curta duração. A veiculação da imagem desses acessórios em material pornográfico custou seu desaparecimento do ambiente de consumo, sobretudo dos catálogos de compra e dos magazines. Foi apenas depois da invenção da pílula anticoncepcional, nos anos 60, e toda a liberação sexual resultante dos movimentos juvenis e feministas, que os vibradores ressurgiram, introduzidos no mercado como artigos sexuais. Alguns dos modelos que foram desenhados a partir da forma do dildo tiveram origem nos sex shops, criados por feministas na década de 70, como o Good vibrations. ${ }^{16}$ Preciado (2002) associa os desenhos contemporâneos do dildo vibrador às influências do movimento feminista e afirma que ele vai além da imitação do pênis: trata-se antes de uma prótese complexa da mão lésbica. As baterias trouxeram de volta, segundo a autora, a mão que masturba que tinha sido retirada por meio de tecnologias da repressão ao onanismo, estimulando a produção do orgasmo longe do contexto terapêutico e fora da relação heterossexual.

Tal articulação entre dildos e feminismo, contudo, está longe de ser tão bem-sucedida. De fato, o uso desses acessórios, cuja forma parece mimetizar o pênis e o perigo simbólico do falo, ainda gera significativo contencioso. Lynda Hart (1998), ao comentar as sex wars $^{17}$ dos anos 80, indica variantes do feminismo radical que consideram que esses objetos, assim como as práticas sadomasoquistas, são imitações das relações heterossexistas, resultantes da dominação patriarcal. ${ }^{18}$ Muitas dessas críticas apresentam uma enorme confluência com aquelas teorias que supõem que a relação entre dildo e pênis seja de substituição. Do ponto de vista dos estudos, Preciado afirma que, em vez de ser tratado como objeto sexual, as poucas reflexões a respeito do uso de dildos por mulheres estão aprisionadas em problemas teóricos relativos à inveja do pênis ou ao falo feminino. ${ }^{19}$ Mais do que uma posição estratégica entre o falo e o pênis, "o dildo é a verdade da heterossexualidade como paródia" (Preciado 2002:68). Sua existência concreta e material parodia as distinções binárias que articulam o sistema heteronormativo (como as oposições pretensamente estáveis entre masculino/feminino e ativo/passivo), e mostra que tais normas são contingentes e arbitrárias. 
Lynda Hart (1998), ao pensar sobre os dildos e as próteses, chama a atenção para uma dupla dimensão que me parece relevante acrescentar. De um lado, o uso desses objetos suplementa, expande ou amplia a natureza limitada da carne humana. De outro lado, essa operação implica remodelar o corpo, moldá-lo segundo novas configurações (movimentos, texturas e até temperatura). Nesse sentido, eles sugerem inscrição, articulação e interpelação. Para esta autora, os dildos expandem a capacidade de agência humana, mas a questão é, se a tecnologia é que faz isso - na ausência de outra agência humana, ou não - depende inteiramente da posição daquele que a usa e de sua localização na fantasia e nas cenas.

Alfred Gell, em estudo que trata a antropologia da arte, traz contribuições para adensar essa reflexão. ${ }^{20}$ Em particular, ele apresenta uma abordagem que fornece maior complexidade às relações entre objetos e pessoas, sobretudo sua indicação em introduzir nessas relações a noção de agência social. Ele utiliza tal conceito no domínio de problemas postos pela antropologia, sem se confundir com as discussões sobre este termo levadas a cabo pela filosofia e seus contenciosos teóricos, o que significa que a agência é atribuível àquelas pessoas - e coisas — que são vistas iniciando sequências causais de um tipo particular, ou seja, eventos causados por atos da mente, ou do desejo, ou da intenção, mais do que à concatenação de eventos físicos. Costumamos atribuir mente e intenções aos animais e aos objetos materiais, mas eles são sempre, em um sentido residual, mentes humanas, na medida em que nós temos acesso apenas às mentes humanas e, mais precisamente, às nossas próprias mentes. $\mathrm{E}$ as nossas mentes são inevitavelmente mentes sociais; da mesma forma, a ação não pode ser conceituada a não ser em termos sociais.

Importante mencionar que onde quer que ocorra a agência humana, ela se realiza no mundo material. A principal implicação de tal argumento é que as "coisas" nas suas propriedades causais como coisas são tão essenciais à operação da agência como os estados da mente que, no entanto, consideramos normalmente como o "motor" inicial de uma sequência causal. Entretanto, a origem e a manifestação da agência tomam lugar em um meio que consiste, em grande parte, de artefatos. Os agentes, nesse sentido, não usam simplesmente os artefatos, podendo, inclusive, ocupar o lugar dos artefatos na sua conexão com os outros seres. Não cabe atribuir consciência à essência dos objetos. Estamos, desde sempre, diante de situações, contextual e socialmente delimitadas, em que é possível presumir que se sinta que as coisas são pessoas, não só pelo afeto investido, mas pelos tipos de relação que emanam dessa interação. Os objetos podem configurar, em cenas particulares, o ativo na relação, assim como, neste setting, o ser humano seria 
o passivo. Há uma intercambialidade possível, uma transitividade a ser considerada. E este é o aspecto para o qual eu gostaria de chamar a atenção: quando estabelecemos uma fronteira rígida entre a autodeterminação das pessoas e a materialidade inerte das coisas, perdemos de vista que pessoas e objetos são igualmente constituídos por agência social, por uma atividade e uma mobilidade de lugares de ação entre eles.

Os toys ou acessórios podem ser analisados a partir desta perspectiva. Nada a estranhar, portanto, que eles sejam agentes relacionados com as mulheres, entre as mulheres, com os homens e entre homens e mulheres. Resta, contudo, desenvolver ainda sobre quais os efeitos dessas relações, quando pensamos em cenários que estão mobilizando práticas eróticas, de forma a não estranharmos perguntar se os acessórios têm gênero e em quais situações, se eles estão ou não implicados em relações de tipo homo ou heterossexual, e se seria descabido afirmar que eles também podem ser tomados como agentes eróticos - do mesmo modo que as pessoas envolvidas e não somente bens eróticos.

\section{Sex toys: acessório, James, Jack, brinquedinho, consolo}

Os depoimentos sobre os usos de toys sugerem que a relação com os objetos implica experiências marcadas pelo trânsito ou a circulação da agência entre os elementos envolvidos. Em diferentes cenas descritas, a atividade ou a passividade sexual pode estar investida na pessoa ou no objeto. A partir das narrativas, nota-se que há mecanismos de personalização que são postos em operação quando, por exemplo, se atribui um nome próprio a um objeto. E existem outros tipos de circulação da agência quando consideramos o modo como os entrevistados se referem a ele: muitos empregam a palavra brinquedo, outros chamam de acessório, para outros tantos faz usar o termo consolo ou a expressão toy. As diferentes designações, os nomes atribuídos e, ainda, como as pessoas escolhem os objetos e suas predileções por forma, tamanho, matéria-prima (se é feito de látex ou silicone ou ainda cyberskin) e cor, sugerem um rico material para extrair implicações.

O esforço mais relevante aqui é o de tentar qualificar melhor — a partir de casos localizados - as diferentes operações relacionais entre pessoas e objetos. Há a relação de substituição quando o objeto é escolhido e usado de maneira próxima ao referente. ${ }^{21}$ Quando o uso é estabelecido de modo a ampliar a natureza limitada da carne humana (Hart 1998), em situações em que avistamos certa distância entre o objeto e o referente, chamo o uso do toy de prótese. O emprego desta palavra, antes de carregar sentido médico 
ou mesmo êmico, associa-se às interessantes sugestões feitas por Preciado (2002) e Hart (1998) sobre tomar os dildos como objetos agrupados como próteses.

Em todas essas operações noto o peso da paródia: evocação satírica ou irônica seja sobre masculinidade, seja sobre feminilidade, ou de diferentes orientações sexuais ou de variadas manifestações de corporalidade.

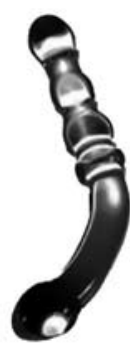

dildo

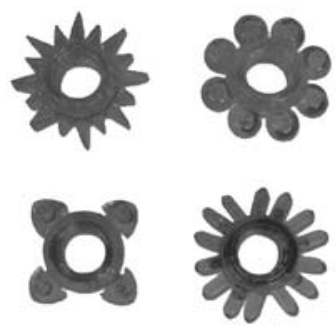

anéis penianos

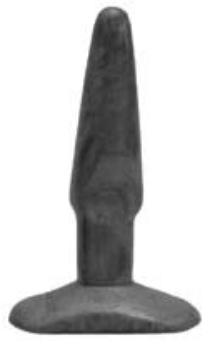

plug

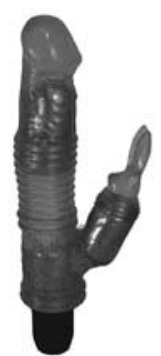

rabbit

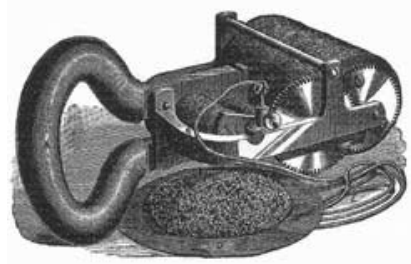

vibrador a vapor

As pessoas entrevistadas usam muitos objetos: dildos com a forma fálica ou de bullets ovalados, vibradores com forma de dildo, rabbits ou butterflys; alguns preferem os plugs e todos usam óleos e gels que lubrificam (alguns esquentam outros esfriam), vestem lingeries transparentes com rendas e cores fortes, enquanto os que simpatizam com as liturgias sadomasoquistas usam algemas, chicotes e cordas (para o Shibari). Todos esses apetrechos são, em seu conjunto, designados como brinquedos, acessórios ou toys. Mesmo a calcinha provocante, a corda ou a algema são qualificadas deste modo, o que significa que também são consideradas como bens eróticos. 
Acessório é uma designação bastante difundida na rede que compõe os sex shops do nicho de alta classe média, cuja característica marcante, como mencionei em estudo a respeito (Gregori 2010), é ser organizado, gerenciado por e para mulheres. As entrevistadas provenientes dessa rede alternam entre as designações de toy e acessório e tal fato me parece revelar a estreita vinculação do uso desses bens no contexto particular de tal mercado. No caso, são pessoas cujo consumo é de alto luxo e não restrito às lojas brasileiras, o que justifica a denominação sex toy, tornando clara a referência às alternativas abertas para as mulheres independentes da classe média urbana norte-americana ou europeia. Não empregam a palavra consolo, pois o uso do toy ou do acessório não sugere uma falta ou uma carência, como indicado pela referência ao "consolo de viúva". O toy é o brinquedo falado em inglês, algo para divertir, um elemento a mais. Acessório é também a palavra empregada pelos agentes de mercado e pelos consumidores para outros produtos, como cintos, sapatos, bolsas, bijouterias. Há nesta designação, portanto, uma operação que avizinha ou similariza os produtos que adornam as vestimentas e o bem erótico. Chamar de toy ou acessório afasta, inclusive, possíveis mal-entendidos em relação a algo que possa ser confundido com vulgaridade.

Longe de reduzir as experiências transgressoras de muitos dos usos e das práticas sexuais das entrevistadas que empregam tais palavras, quero assinalar que o modo de designação exprime certas fronteiras de status, bem como aquelas atinadas com as normas de gênero e sexualidade. Até para expandir as opções e as experimentações sexuais, é preciso ter certa etiqueta para não assustar, radicalizar ou confundir.

Brinquedo erótico é expressão recorrente nas entrevistas, mais frequente do que toy ou acessório e, mesmo estando hoje bastante difundida, parece ter sido introduzida em meio às ações de prevenção às DST/Aids para ensinar e estimular o uso de camisinhas através das oficinas promovidas por organizações não governamentais e entidades políticas e de saúde desde meados dos anos 80. Uma de nossas entrevistadas faz parte dessa rede e, mais do que a mera informação da história do uso da palavra, ela afirma que o sentido de brinquedo está associado a ser:

[...] uma coisa de criança. Um lance que criança me ensinou que é muito parecido com brincadeira erótica. A gente pergunta: isso aqui é uma espada? A gente é tão besta, adulto é tão imbecil... Aí a criança responde: é uma espada na hora que eu quero que seja uma espada, se não vira uma vara de condão ou uma arma na hora que eu quero. Então, brinquedo erótico e cena erótica é uma coisa meio igual para a criança, de transformar aquilo ao seu bel prazer naquele momento. 
A associação parece sugerir, portanto, que os bens eróticos podem ser investidos de múltiplas faces, o que reforça sua qualidade transitiva: mais do que uma palavra que as crianças empregam - brinquedo - o que importa é remarcar a operação infantil de fazer uso de objetos que podem ser transformados conforme a imaginação e o desejo. Em certo sentido, chamar os objetos de tal modo aproxima a prática sexual dos adultos dos polimorfismos infantis. Mas antes de expressarem uma imaturidade, me parece que são recursos que indicam a natureza contingente e dinâmica das experiências sexuais que estão sendo tentadas. Indicam também operações em que a atividade ou a passividade pode circular entre o brinquedo e a pessoa. Uma menção comumente feita nos relatos, e que implica esses trânsitos, é quando, por exemplo, se usa o diminutivo para designá-los, como brinquedinho ou gosto daqueles coloridinhos. A referência lúdica está sempre presente, embora, nesses casos, ela pareça evocar a infantilização do objeto para o desfrute da pessoa, a qual seria aí o ativo e a infantilização seria um modo de tornar o objeto passivo.

Uma operação inversa seria a de investir o objeto de uma espécie de pessoalização, como nos casos em que há atribuição de nomes próprios aos dildos, como James ou Jack, e as referências a momentos ou a cenas de uso em que, mesmo controlando o toy com as mãos, a pessoa cria uma cena em que recebe passivamente do objeto a ação que lhe proporciona prazer. Três entrevistados, dois homens (autodeclarados gays) e uma mulher (bissexual assumida), disseram dar esses nomes aos seus brinquedos. Interessante remarcar que os nomes foram dados a objetos que imitam o pênis, e a referência ao nome James apareceu em dois casos. Vejamos:

$\mathrm{P}$ - E como você escolhe esses nomes?

$\mathrm{R}$ - Ah! É coisa que surge. Numa brincadeira... o último foi... a gente deu o nome de James pro meu consolo. A gente 'tava brincando e o cara falou: "E aí? Vou chamar o reforço..." (risos). E aí saiu um James não sei por que e ficou. Até hoje, com ele eu uso o mesmo nome (moça, 30 anos, jornalista, bissexual).

O mesmo nome foi atribuído pelo rapaz homossexual (também 30 anos e jornalista) que, quando indagado sobre se comprava os brinquedos que dizia usar, falou:

Comprar, comprar mesmo, eu comprei uma vez um consolo. Eu fui num sex shop comprar filme pornô e eu achei aquele consolo tão parecido com o real, até na consistência, aí comprei e dei o nome dele de James. E já, dentro do casamento, uma vez ou outra eu me masturbei usando o James. 
$\mathrm{P}$ - E por que o nome James?

R - Não sei, falei "vou dar um nome". É feio falar consolo e tal, aí dei o nome pra ele. Tinha $18 \mathrm{~cm}$ o James. Depois, eu emprestei pra uma amiga e ela nunca mais me devolveu. Ela foi usar com o namorado e deve estar com ele até hoje. E eu não quis mais o James de volta.

James é um nome comumente associado a um chauffeur ou mordomo. Este parece ser o sentido da escolha do nome, ainda que não explicitado pela entrevistada no primeiro trecho apresentado. O namorado chama um reforço, e o James aparece. A situação sugere, portanto, a presença de um terceiro elemento entre os parceiros: um elemento que, com ironia, implica a associação com um empregado. Há, de fato, uma prática entre homens de nomear o seu órgão, mas os nomes normalmente são em português, como Bráulio, nome já de domínio público. Na situação descrita, parece haver uma cuidadosa operação de convidar um terceiro personagem para compor a cena erótica e, nela, ele ocupará outro lugar, realizando função distinta da do namorado: ele está vindo em auxílio e ocupa uma posição de apoio. Percebe-se que o uso paródico do nome acaba, de certo modo, por proteger as habilidades viris do namorado.

Já o James, do segundo trecho, é convidado para as práticas solitárias do entrevistado, parecendo expressar outro tipo de desejo. A escolha do nome, na situação descrita, também pode estar ligada ao personagem de folhetim: o motorista. Mas não seria, então, um personagem auxiliar ou secundário. Chama a atenção, na cena descrita, a associação do nome a algo que pareceria ser tão real. Vale assinalar que o consolo, com aparência realística, mais do que real é hiperreal. Há nele uma tentativa inegável de aproximar o objeto do pênis: a semelhança é cuidadosamente buscada em razão dos relevos de enervações, a forma da glande e a cor da pele. O modelo, no entanto, supera o real, ganhando uma forma idealizada: o que evoca a pele branca, por exemplo, traz um roseado que só encontramos em recém-nascidos, e os de pele "negra" são mais pretos que o ébano; além disso, os tamanhos podem ser variados, contudo, exuberantes. São vendidos com diferentes texturas e, na situação descrita pelo entrevistado, a escolha foi pela rigidez do látex. O tamanho acentua ainda mais o sentido da operação: no caso, a escolha indica uma clara tentativa de atribuir virilidade ao objeto. O James, que inclusive pode ser emprestado para uma amiga, pode também não interessá-lo mais. Há nessa relação com o objeto, neste caso, uma clara paródia da masculinidade viril, da importância que ela tem nas fantasias gays contemporâneas (Braz 2010), e o jogo de colocá-la à sua disposição: ver como é experimentar o James e, depois, não querê-lo de volta. 
A transitividade ou o trânsito entre ativo e passivo não esgota todas as possibilidades para pensar as interações entre as pessoas e os objetos. Em alguns casos, a relação parece ser de substituição: situações narradas em que o dildo é o substituto presencial do namorado que mora em outro país, fazendo sexo via internet. Ou, ainda, a cena em que a jovem sente que se masculiniza ao vestir o pênis, como ela mesma se refere, para penetrar a namorada. Neste último caso, a entrevistada é declaradamente lésbica e nunca se relacionou sexualmente com um homem. É bastante reservada e até monossilábica ao se referir aos objetos - usa um dildo e o veste com uma cinta, depois de muita negociação e tentativas da namorada. A relação de substituição aí se estabelece entre dildo, pênis e sua conotação direta com a masculinidade. Essa articulação incomoda a entrevistada, a ponto de alegar ter sentido prazer apenas tardiamente.

Em outras situações e para outras pessoas, mesmo diante de operações do tipo substituição, há maior eloquência e divertimento. A mulher bissexual, cuja trajetória sexual foi narrada com a eloquência da Juliette do Marquês de Sade, discorreu na entrevista sobre o ciúme que teve de seu brinquedo na relação com uma companheira e do uso combinado que fez dele com seu atual marido, no sexo via internet, durante o ano em que ele vivia fora do Brasil. Ela conta que ganhou um dildo, que chama de "pinto", de um amigo, em meados dos anos 90. Naquela época, era casada com uma mulher e foi sua primeira tentativa de usar o brinquedo acompanhada:

Usei esse pinto com Maria. Não foi legal. Não gostei. Fiquei com ciúme do pinto.

$\mathrm{P}$ - A ideia era que ele era um brinquedo seu pra você brincar?

$\mathrm{R}$ - É. Acho que por isso eu joguei ele fora. Eu não queria compartilhar ele com ninguém. Imagina meu atual marido pegar o meu pinto! Nem que fosse pra enfiar em mim. Não queria.

$\mathrm{R}$ - Joguei ele fora agora, quando meu marido chegou.

$\mathrm{P}-12$ anos com o mesmo brinquedo...

R - Nunca tinha pensado nisso! (risos) Nunca tinha feito essa conta!

$\mathrm{P}$ - Foi seu companheiro de mais tempo!

$\mathrm{R}$ - (risos e bate palmas). Esse foi o meu maior casamento!

Neste exemplo, a substituição evoca outro ser, a ponto de não querer partilhá-lo seja com uma companheira, seja com o atual marido - a convivência dele com o objeto foi virtual. Ela estabelece uma ligação direta dildo e pênis, inclusive ao alegar que sua fantasia estabelecia uma semelhança entre os dotes do brinquedo e os do marido. Neste caso, mas também no 
anterior, é feita uma operação metafórica entre o objeto e um referente, sendo este o órgão sexual ou o sexo da pessoa e ainda o gênero que ela porta. É importante remarcar que estamos diante de usos que sugerem uma substituição, mas ela, diferente da interpretação tentada pelo feminismo radical, não me parece imitar ou reproduzir o modelo falocêntrico. A substituição é feita, mantendo presente uma tensão entre a semelhança e o simulacro. Simulacro é uma cópia que se exibe como uma reprodução imperfeita ou, como nos termos de Deleuze (1988), ${ }^{22}$ uma imagem que ainda produz um efeito de semelhança, importante para revelar o deslocamento que a simulação pretende.

Além da substituição, o uso pode indicar que o objeto seja tomado como uma prótese, no sentido sugerido por Hart (1998) e Preciado (2002), suplementando as limitações da carne. Algumas pessoas entrevistadas explicitaram não gostar de imitações dos genitais.

$\mathrm{P}$ - Esse brinquedo que você usa, tem cor?

$\mathrm{R}$ - É azul brilhante.

$\mathrm{P}$ - Você escolheu pela cor?

$\mathrm{R}$ - Escolhi pela cor, ele é brilhante!

$\mathrm{P}$ - Você acha que tem alguma associação? As cores aparecem muito nos seus brinquedos. Você acha que é um jeito de personalizar? Você dá nome?

$\mathrm{R}$ - Tem um nomezinho sim. O que é só meu tem um nome, o que era nosso — meu e da minha namorada — não tinha nome. [...] eu acho que tem essa personalização. Eu preferi escolher um mais colorido, mais bonito e de uma cor que pra mim faz diferença. Eu gosto de azul e peguei o brilhante porque achei mais feliz. Eu gosto que ele vibre, ele fica se mexendo ali sozinho, é divertido.

A escolha das cores, nesses usos protéticos, resulta em um esforço de criação que vai além das associações dildo/genitais. A plasticidade dos objetos, nessas situações, é invocada com vigor: cores brilhantes que sugerem felicidade, ou a vibração que faz com que eles se movam sozinhos, parecendo ser outros seres. Há também o caso das pessoas que escolhem os plugs, objetos com uma forma cônica e que foram inventados para o uso anal, como neste caso a seguir, de uma jovem que se relaciona com meninos e meninas e gosta bastante de toys:

$\mathrm{P}$ - Me fala dessas preferências, porque o plug foi uma coisa criada, pelo menos do ponto de vista do mercado, para o segmento gay masculino. E esta é a sua escolha, o que você mais curte...

$\mathrm{R}$ - É o que eu gosto mais. [...] e o que eu mais gosto é do laranjinha. 
$\mathrm{P}$ - E por que você gosta mais dele, é por causa da cor ou da forma ou dos dois?

$\mathrm{R}$ - Não sei, acho que pela cor e pela forma. Ele tem uma basezinha, meio quadrada, retangular, na verdade, e aí ele vem, não é muito grosso e vai afinando e acaba ficando meio assim uma arvorezinha de natal, um pinheirinho...

O uso a partir de uma relação protética sugere que o objeto venha a suplementar ou a expandir a associação figurativa entre dildo/genitais. Formas e cores convidam a outras possibilidades de fantasia. Chama a atenção essa articulação entre o toy, o plug, descrito a partir de uma narrativa que emprega eloquentemente os diminutivos e o pinheiro de natal. À primeira vista, poder-se-ia interpretar o caso como expressão que revela alguém ainda enlaçada à fase anal. Antes, me parece ser um caso de deslocamento paródico: a referência infantil, o gosto pelo anal e com um objeto que não imita o pênis têm o sentido aí de arremedo, um divertimento produzido a partir de convenções patologizantes.

Como tenho insistido, os usos, em variadas cenas descritas pelos entrevistados, parodiam aspectos que compõem as normas de gênero, de sexualidade e também as que implicam uma fronteira rígida entre sujeito e objeto ou pessoas e coisas. As paródias são realizadas como imitações burlescas, como no caso do entrevistado que classifica seus acessórios para as práticas sadomasoquistas, inflexionando em gênero: o chicote é masculino e, de preferência, rústico; a algema é feminina, pois brilha e pode ser tomada como um adorno. A ausência de nuance e essa explicitação do senso comum sugerem, menos do que falta de sofisticação, um arremedo. Outro entrevistado traz mais um exemplo do uso dos objetos a partir da paródia: ele conta que escolheu para si uma pica vermelha em homenagem ao socialismo e, em particular, ao Partido dos Trabalhadores. Interessa lembrar que as paródias que articulam sexo e política têm longa tradição, basta ilustrar com as obras de Sade e toda a sátira política que as envolve.

O alcance teórico do uso de objetos em forma de paródia é o de indicar uma operação entre o referente e o simbolizado que não é de semelhança, mas de deslocamento. Não se trata de mimese, mas de mímica, como sugerido por Homi Bhabha (1994) a respeito da colonial mimicry. A mímica ou paródia - é um modo de expor as normas à ambivalência. O exagero e o burlesco abrem para o ridículo e para a crítica. Se não para a crítica, ao menos sugerem que as prescrições normativas podem servir para outros usos. São precisamente esses deslocamentos que interessam ser retidos na análise das narrativas dos usuários de sex toys: usos que sugerem como as prescrições de gênero podem servir para, em vez de reproduzir as assimetrias que alimentam a desigualdade, gerar formas de prazer. 
De fato, os efeitos das novas formas de erotismo sobre as convenções de gênero e sexualidade são variados. Estas novas formas expandiram a tolerância e o âmbito de experimentações sexuais, como fica claro pela diversidade de usos de bens eróticos. A dimensão vivencial dos usuários desses objetos eróticos e suas experiências narradas, ao assinalarem uma vívida sexualidade polimorfa, revelaram, de um lado, a desestabilização da matriz que enlaça sexo, gênero, sexualidade e desejo a partir do modelo do dimorfismo sexual; de outro lado, a transitividade da agência entre pessoas e objetos mostra a limitação das teorias que desconsideram a importância do mundo material sobre as relações sociais, sobre as pessoas e seus corpos.

Maria Filomena Gregori é professora do Departamento de Antropologia da Universidade Estadual de Campinas (Unicamp) e pesquisadora do Núcleo de Estudos de Gênero (Pagu/Unicamp). E-mail: <bibiagregori@uol.com.br>

\section{Notas}

${ }^{1}$ Freud afirmou nos Três ensaios sobre a sexualidade (1972 [1905]) que a perversão seria o negativo da neurose. Esta afirmação implica que a neurose é uma forma de recalque das fantasias perversas e que a perversão seria expressão direta das pulsões parciais gestadas na infância, driblando os recalques. Alguns autores indicam que foi apenas a partir de 1905 que Freud elaborou a noção - que aparece de modo explícito em "Bate-se numa criança" (1919) - de que as perversões podem ser tomadas como formações defensivas, em particular, como forma de lidar com a angústia da castração (Rudge 2004).

${ }^{2}$ Tais depoimentos foram coletados a partir de entrevistas, em profundidade, realizadas com 16 pessoas que compõem três redes de investigação: a primeira delas foi construída a partir da pesquisa de campo, junto aos diferentes sex shops de São Paulo e do Rio de Janeiro, e resultou em quatro entrevistas com mulheres heterossexuais, de classe média e média alta, entre 40 e 50 anos; a segunda rede foi formada na pesquisa de doutorado de minha aluna Regina Facchini e contou 
com entrevistas de dois homens heterossexuais, de classe média, entre 30 e 50 anos, um homem e duas mulheres bissexuais, de classe média, entre 20 e 40 anos, e mais um homem homossexual, de classe média, entre 20 e 30 anos; a terceira e última rede foi formada a partir dos contatos de pesquisa de outra aluna, Carolina Parreiras: duas mulheres bissexuais entre 20 e 30 anos, de classe média, duas mulheres homossexuais entre 20 e 30 anos, também de classe média, e dois rapazes homossexuais, entre 20 e 30 anos e de classe média. Importante salientar que tive o cuidado de conseguir entrevistas que pudessem estabelecer um leque comparativo mais amplo: mulheres, homens, diferentes orientações sexuais e faixas etárias compondo um quadro comparativo entre pessoas jovens e mais maduras (o escopo, no caso, ficou entre 20 e 50 anos) de diferentes extratos de classe média. A ampliação, nesse caso, não visou estabelecer correlações entre comportamentos e marcadores sociais de diferença. Antes de serem representativas, essas entrevistas (ricas em sua diversidade) fornecem material eminentemente qualitativo e exemplar para os propósitos analíticos elencados.

${ }^{3}$ Como assinala Michel Foucault (1976), tais dispositivos - que mobilizam variadas estratégias desde o século XVIII - instauraram a ideia moderna que temos de "sexo", essa espécie de unidade fictícia que agrupa elementos anatômicos, funções biológicas, condutas, sensações e prazeres. Judith Butler (1990) chama essa unidade fictícia de matriz da heterossexualidade compulsória, cuja operação faz combinar, segundo um movimento de homologia, o corpo sexuado (do homem e da mulher com seus respectivos genitais), o conjunto de atributos de gênero (que conforma masculinidades e feminilidades) e o comportamento ou a orientação sexual (que indica heterossexualidade ou homossexualidade). Conceitualmente, é fundamental a noção de que os processos em que tais homologias são realizadas são apagados, de modo a se acreditar que a matriz heterossexual define os padrões de normalidade da sexualidade porque constitui a natureza. Assim, seria antinatural, por exemplo, ser um homem e não dispor de um corpo com genitais de homem, ou ser homem e não comportar-se a partir de parâmetros masculinos ou, ainda, ser homem e praticar sexo com outros homens. A matriz heterossexual naturaliza uma espécie de composto que é simultaneamente sexual e de gênero, corpóreo e comportamental e de modo dimorfômico, ou seja, a partir de uma relação que define a diferença em termos de incomensurabilidade e de uma complementaridade necessária entre homem e mulher, masculino e feminino, pênis e vagina.

${ }^{4}$ Nascida no bairro de Interlagos, na capital paulista, de pai mineiro, torneiromecânico, e de mãe cearense, gerente de finanças, ela fez curso de teatro, de circo e podia namorar em casa. A educação sexual recebida na escola pública e na faculdade, segundo ela, foi muito teórica. A referência mais importante, além do pai e da mãe (que tinham livros sobre sexualidade na biblioteca da casa), veio da experiência com o grupo de mulheres É de Lei.

${ }^{5}$ As referências a Juliette são inúmeras nas obras do Marquês de Sade. Destaco, em particular, os livros Justine, ou os infortúnios da virtude (1968) e Histoire de Juliette (1987). 
${ }^{6} \mathrm{O}$ termo convenções, além do significado presente no dicionário que o define como tudo aquilo que é tacitamente aceito por uso ou consentimento geral, também apresenta o sentido conceitualmente proposto por Roy Wagner que interessa aos propósitos desta reflexão. Em seu Invention of culture (1981), ele assevera que a vida social é feita mediante a relação dialética (no sentido amplo e grego de tensão ou alternação entre termos que são contraditórios, porém, interdependentes) entre convenção e invenção. A convenção tem a ver com o ponto de vista coletivo, com a orientação da cultura, com o modo como as pessoas aprendem a experenciar, agir e comunicar; as convenções sofrem mudanças, e novas inflexões são inventadas, a partir de operações de diferenciação e particularização, no marco de contextos anticonvencionais.

${ }^{7}$ Além das experiências sociais relacionadas ao dildo, são também consideradas por ela como estratégicas as relações contratuais sadomasoquistas e a erotização do ânus. Desde sua filiação à análise da heterossexualidade como regime político de Monique Wittig à conceituação dos dispositivos da sexualidade modernos, formulada por Michel Foucault, e também à política cyber de Donna Haraway, Preciado entende que estas são práticas contrassexuais, na medida em que expressam derivas radicais em relação ao sistema sexo/gênero.

${ }^{8}$ A autora menciona o psiquiatra darwinista T. Clifford Allbutt e seu artigo "Nervous diseases and modern life" (1895) e assinala a compatibilidade das noções de tal vertente com as teorizações sobre a diferença sexual, como as elaboradas pelos sociobiólogos P. K. Geddes e J. A. Thompson no The evolution of sex (1889). Neste livro, os autores elaboram a abordagem sobre tal diferenciação baseada no metabolismo celular: as células masculinas seriam catabólicas, ativas e energéticas enquanto as femininas seriam anabólicas e constituídas para conservar energia, de modo passivo. As doenças nervosas seriam resultantes de um estímulo social não condizente com a estrutura celular feminina, passiva, plácida e altruísta (Showalter 1987:121/2).

${ }^{9}$ Embora a psiquiatria darwinista associasse com maior vigor a histeria a ocorrências fisiológicas decorrentes da puberdade, médicos como Horatio Bryan Donkin, que escreveu o verbete sobre a doença para o Dictionary of psychological medicine (1982), embora socialista e próximo dos círculos feministas, também preferiu o argumento biológico de que a desordem era resultante de uma insatisfação sexual (Showalter 1987:131).

${ }^{10}$ Diferente das visões pregressas, ele observou atentamente que os sintomas histéricos são produzidos não por danos físicos, mas por emoções que as pacientes não conseguiam controlar. Freud estudou com ele por um ano, mas já tinha conhecimento de um procedimento empregado por Breuer em sua paciente mais famosa, Bertha Pappenheim (mais conhecida como Anna O.): o talking cure. Levou ao conhecimento de Charcot tal técnica, porém este se mostrou indiferente. De fato, a hipnose foi um episódio no tratamento deste caso, sendo Bertha a primeira pessoa em quem se empregaram os preceitos da análise psicanalítica. Freud teve também um caso paradigmático de paciente histérica, Dora (cujo nome verdadeiro era Ida Bauer) e, por meio da análise, penetrou os mistérios sexuais que resultavam em seus sintomas. Agradeço a Marilucia Melo Meireles ter lido com atenção e corrigido as referências sobre Freud e a histeria. 
${ }^{11}$ São variadas as referências sobre a criação do vibrador, como o catálogo The new good vibrations guide to sex (Winks e Semans 1997) ou guias como Sex toy, elaborado por Em and Lo (2006). Rachel P. Maines (1999) talvez seja a referência mais confiável. Seu livro The technology of orgasm: hysteria, the vibrator, and women's sexual satisfaction apresenta algumas das informações que trago no texto e é bastante citada, seja nos estudos especializados (como de Preciado), seja nos dados de enciclopédia (como no caso da Wikipedia, the free encyclopedia). A informação sobre o invento de George Taylor eu extraí do site eroticpoint.com.br. Maines localiza a primeira referência aos vibradores nos anos 80 do século XIX e menciona os médicos Clinton Melendres e Kelsey Stinner. Além deles, Preciado (2002) indica outro médico que utilizava vibradores como instrumento terapêutico da histeria: John Butler.

${ }^{12}$ Em 1907, foi patenteada nos EUA a primeira capa peniana (desenvolvida por Louis Hawley); 1927 foi o ano de lançamento do gel KY, introduzido inicialmente por médicos para facilitar os exames ginecológicos (o uso do KY como lubrificante sexual será difundido apenas a partir da década de 80). Na década de 40, foi criado o primeiro modelo de boneca inflável, dizem que por cientistas, durante a Segunda Guerra, de modo a regular o apetite sexual dos combatentes e evitar a proliferação de doenças venéreas. Todos estes dados foram extraídos do site eroticpoint.com.br.

${ }^{13} \mathrm{O}$ médico sexologista Vern Bullough (1987) identificou, entre 1856 e 1917, vinte instrumentos diferentes para prevenir a masturbação.

${ }^{14}$ Thomas Laqueur (2003), ao tratar da história cultural do sexo solitário, localiza, em 1712, com a publicação do tratado inglês anônimo Onania: the heinous sin of self pollution, and all its frightful consequences, in both sexes considered, a mudança do sentido da masturbação como pecado para os significados seculares de doença e decadência. Essa nova inflexão só foi possível no cenário cultural ambientado no Iluminismo e a partir das preocupações com a formação individual (Laqueur 2003:22).

${ }^{15}$ Em 1921, foram divulgados na Heart's Magazine vibradores portáteis como presentes de maridos para suas esposas (ver site eroticpoint.com.br). Também é importante destacar que o uso de técnicas de cura da histeria foi se tornando crescentemente obsoleto no correr do século XX.

${ }^{16}$ Em \& Lo (2006) afirmam que Joani Blank, a feminista que criou a Good vibrations, quando trabalhava com mulheres pré-orgásmicas, costumava indicar um vibrador importado do Japão, o Hitachi Magic Wand. Atribui-se a esse vibrador e aos seus resultados para o prazer das mulheres a fonte de inspiração para a criação da loja e do empreendimento. Para maior detalhamento, consultar Gregori (2010).

${ }^{17}$ As sex wars se referem a um momento particularmente significativo na história do ativismo feminista norte-americano, do final dos anos 70 até o início dos anos 90 do séc XX, cujos efeitos resultaram em uma reconfiguração do campo político e teórico. Em meio à ameaça da retomada da moralidade tradicional por intervenção do Partido Republicano e de lideranças religiosas (a partir de um movimento conhecido 
como New Right), apareceram no cenário político feminista grupos com posições antagônicas. De um lado, grupos antipornografia que compõem o que os especialistas chamam de feminismo radical; de outro lado, grupos pro sex, organizados em torno de minorias sexuais. Para maior detalhamento, consultar Gregori $(2003,2010)$; Hanssen (2000); Butler (1997).

${ }^{18}$ Algumas feministas chegaram, inclusive, a afirmar que o sexo entre mulheres com o dildo não é verdadeiramente lésbico (Hart 1998; ver também Preciado 2002).

${ }^{19}$ Um estudo interessante e que, segundo Preciado, constitui exceção a essa tendência é o de Judith Halberstam, Female masculinity (1994). Entre as autoras criticadas por ela está Teresa de Lauretis (1994), figura relevante do campo das teorias feministas. Ela estaria presa, segundo a filósofa espanhola, a essa tendência, sobretudo pelo fato de seus comentários sobre os dildos em Practice of love estarem apenas situados em meio às críticas ao heterocentrismo de Lacan. De Lauretis só vê o potencial crítico dos dildos em vista da pretensão do pênis em fazer-se passar por falo. Preciado também critica Judith Butler (e faz referência ao Bodies that matter), alegando que a questão do dildo estaria oculta na problemática mais ampla do falo lésbico.

${ }^{20}$ O livro de referência é Art and agency - an anthropological theory (1998), publicado um pouco depois da morte de Alfred Gell.

${ }^{21} \mathrm{O}$ referente, no caso, pode ser o pênis e a vagina como partes corporais ou, ainda, aquilo que está investido de um sentido que provoca e satisfaz o desejo: o falo ou o fetiche (por exemplo, por pés e sapatos), considerando que o referente pode ser também uma pessoa.

${ }^{22}$ Deleuze, ao pensar sobre Diferença e Repetição, visita as distinções estabelecidas por Platão entre original e imagem (modelo e cópia, ídolo e ícone) e, a partir de um desenvolvimento mais profundo, a distinção entre duas espécies de imagem: os ícones - as boas imagens, as que se assemelham do interior com o original - e os simulacros - as más imagens, os fantasmas, "o falso pretendente sempre disfarçado e deslocado" (Deleuze 1988:211). Para o autor, "o simulacro (ou fantasma) não é simplesmente uma cópia de cópia, uma semelhança infinitamente diminuída, um ícone degradado [...] o simulacro é precisamente uma imagem demoníaca, destituída de semelhança; ou melhor, contrariamente ao ícone, ele colocou a semelhança no exterior e vive de diferença. Se ele produz um efeito exterior de semelhança é como ilusão e não como princípio interno" (id:212). 


\section{Referências bibliográficas}

BHABHA, Homi. 1994. The location of culture. London: Routledge.

BRAZ, Camilo Albuquerque de. 2010. À meia-luz... Uma etnografia imprópria sobre clubes de sexo masculinos. Tese de doutorado, Instituto de Filosofia e Ciências Humanas, Universidade Estadual de Campinas - Unicamp.

BUTLER, Judith. 1990. Gender trouble: feminism and the subversion of identity. New York: Routledge. 1997. Excitable speech: a politics of the performative. New York: Routledge.

CARTER, Angela. 1978. The sadeian woman - and the ideology of pornography. New York: Panteon Books.

DELEUZE, Gilles 1988. Diferença e repetição. São Paulo: Editora Graal.

EM \& LO. 2006. Sex toy. São Francisco: Cronicle Books.

FOUCAULT, Michel. 1976. História da sexualidade: a vontade de saber. Rio de Janeiro: Graal.

FREUD, Sigmund. 1972 [1905]. Um caso de histeria - três ensaios sobre a sexualidade e outros trabalhos. Edição Standard Brasileira das Obras Psicológicas Completas de Sigmund Freud. Rio de Janeiro: Imago Editora.

ELL, Alfred. 1998. Art and agency. Oxford: Oxford University Press.

GREGORI, Maria Filomena. 2003. "Relações de violência e erotismo". Cadernos Pagu, 1(20):87-120.

. 2010. Prazeres perigosos. Erotismo, gênero e limites da sexualidade. Tese de Livre Docência, Departamento de Antropologia, IFCH - Unicamp.

HALBERSTAM, Judith. 1998. Female masculinity. Durham: Duke University Press.
HANSSEN, Beatrice. 2000. Critique of violence. New York: Routledge.

HART, Lynda. 1998. Between the body and the flesh - performing sadomasochism. New York: Columbia University Press.

LAQUEUR, Thomas. 2003. Solitary sex: $a$ cultural history of masturbation. New York: Zone Books.

LAURETIS, Teresa de. 1994. The practice of love - lesbian sexuality and perverse desire. Bloomington and Indianapolis: Indiana University Press

MAINES, Rachel. 1999. The technology of orgasm: hysteria, the vibrator, and women's sexual satisfaction. Baltimore: John Hopkins University Press.

PRECIADO, Beatriz. 2002. Manifiesto contrasexual. Madrid: Opera Prima.

RUBIN, Gayle; BUTLER, Judith. 2003. "Tráfico sexual: entrevista". Cadernos Pagu, 21:157-209.

RUDGE, Ana Maria. 2004. "Aspectos do discurso perverso". Revista del Centro Psicoanalítico de Madrid. Disponível em: www.centropsicoanaliticomadrid.co/revista/6/art4.html.

SADE, Marquês. 1968. Justine ou os infortúnios da virtude. Rio de Janeiro: Saga. . 1987. "Histoire de Juliette". In: Oeuvres complètes. Tomo I. Paris: Pauvert.

SHOWALTER, Elaine.1985. The female malady: women, madness and english culture, 1830-1980. London: Virago.

WAGNER, Roy. 1981. The invention of culture. Chicago: University of Chicago Press.

WINKS, Cathy; SEAMANS, Anne (orgs.). 1997. The good vibrations guide to sex: the most complete sex manual ever written. San Francisco: Cleis Press. 
Resumo

Este artigo apresenta uma discussão em torno das articulações entre pessoas, corpos e objetos e seus efeitos sobre as normas de gênero e de sexualidade, a partir de depoimentos de usuários de acessórios eróticos. As relações implicadas nos usos e nas práticas desses objetos sugerem, em particular, experiências de deslocamento entre sexo e gênero, corpo e matéria, sujeito e objeto, presença e virtualidade.

Palavras-chave Erotismo, Gênero, Sexualidade, Antropologia dos objetos, Formas Contemporâneas de Erotismo.

\section{Abstract}

This article presents a discussion on the interconnections between people, bodies and objects and their effects on norms relating to gender and sexuality, based on statements given by users of erotic accessories. The relationships implied in the uses and practices surrounding these objects suggest, in particular, experiences of displacement between sex and gender, body and matter, subject and object, bodily presence and virtuality. Key words Eroticism, Gender, Sexuality, Anthropology of Objects, Contemporary Forms of Eroticism. 